\title{
Clinical and surgical features of lower brain stem hemangioblastomas in von Hippel-Lindau disease
}

\author{
Giacomo Pavesi - Silvia Berlucchi • Marina Munari • \\ Renzo Manara • Renato Scienza • Giuseppe Opocher
}

Received: 20 July 2009 / Accepted: 8 September 2009 /Published online: 29 September 2009

(C) Springer-Verlag 2009

\begin{abstract}
Background In the context of von Hippel-Lindau disease (VHL), the medulla oblongata is a relatively frequent site of growth of hemangioblastomas, posing related clinical and surgical difficulties. Their management requires a close correlation between clinical evolution and morphological surveillance. In order to describe their clinical and surgical features, we reviewed our experience in the treatment of these lesions.

Methods Between 2001 and 2009, 14 patients (9 female and 5 male, mean age 34 years) underwent removal of 15 lower brain stem hemangioblastomas. Based on the review of the clinical records and outpatient long-term follow-up visits, their clinical course was analyzed. Functional evaluation was measured with the Karnofsky Performance Scale (KPS) on admission, at discharge and at the last follow-up. The mean follow-up period was 30.8 months (range 4-99).
\end{abstract}

G. Pavesi $(\bowtie) \cdot S$. Berlucchi $\cdot$ R. Scienza

Neurosurgery, Padua Hospital,

Via Giustiniani 1,

35100 Padova, Italy

e-mail: giacomo.pavesi@sanita.padova.it

\section{Munari}

Department of Pharmacolgy and Anesthesiology,

Padua University Hospital,

Padova, Italy

R. Manara

Neuroradiology, Padua Hospital,

Padova, Italy

\section{G. Opocher}

Familial Cancer Clinic, Veneto Institute of Oncology

and Department of Medical and Surgical Sciences,

University of Padua,

Padova, Italy
Results All the operated hemangioblastomas were located in the dorsal medulla oblongata, in the context of multiple lesions, cerebellar and/or spinal. In ten patients hemangioblastomas were located in a median position at the obex area; in four cases a lateral location was observed. Cystic component was absent in two cases. Clinical onset preceded surgery by a mean of 8.5 months. Preoperatively three patients showed a KPS lower than 80 , ten patients between 80 and 90 , and one patient scored 100 (asymptomatic). There was no surgical mortality. Nine out of 14 patients showed a temporary surgical morbidity. One patient required a tracheostomy. At follow-up ten patients scored a KPS better than before the operation, while the other four patients remained stable. Permanent morbidity was observed in three patients.

Conclusions Lower brain stem hemangioblastomas in the context of VHL show an often gradual onset of signs and symptoms except for patients who develop an obstructive hydrocephalus. Although transient surgical complications are possible, surgery provides favorable long-term results.

Keywords Hemangioblastoma · von Hippel-Lindau disease $\cdot$ Microsurgery $\cdot$ Brain stem

\section{Introduction}

Although hemangioblastomas are histologically benign tumors, their operative management can be challenging, especially with brain stem locations. Since VHL patients frequently harbor multiple hemangioblastomas, surgery is recommended for symptomatic or rapidly growing lesions in a complex clinical context, requiring a close MR-based imaging follow-up $[1,15]$.

CNS involvement in VHL comprises, in order of frequency, cerebellar, spinal, brain stem and supratentorial hemangioblastomas. Brain stem hemangioblastomas fre- 
quently grow in the lower third of the brain stem, at the obex or in the postero-lateral aspect of the medulla oblongata [4]. The aim of this study was to review all patients with VHL disease-associated medullary hemangioblastomas who underwent surgery in our neurosurgical unit, in order to highlight their clinical behavior and to assess the safety and efficacy of surgical treatment.

\section{Patients and methods}

Since von Hippel-Lindau disease is a neoplastic autosomaldominant syndrome predisposing the patients to develop CNS hemangioblastomas and several lesions in many organs, affected individuals are periodically followed by a multispecialist team, composed of endocrinology, neurosurgery, urology and nephrology, ophthalmology, general surgery, radiology and molecular genetic specialists (VHL Padua network). The evaluation protocol includes VHL genetic testing, blood and urinary analysis, audiometric and ophtalmological examinations; cerebral, spinal and abdominal MRs are obtained. Follow-up evaluations are planned at intervals of $3,6,12$ and 24 months, and then every 2 years unless closer examinations are necessary. Since 2000 the VHL Padua Network has been following 120 affected individuals. A medullary location of CNS hemangioblastomas was found in 22 individuals (18\%) in our patient population; among them 14 individuals were submitted to surgical removal of a lower brain stem hemangioblastoma (6 patients were part of a previously published series [15]). Their overall physical conditions were scored according to KPS at the moment of admission, at discharge and during the last follow-up evaluation. All patients with brain stem hemangioblastomas presented one or more other CNS lesions (without considering retinal angiomas). A complete molecular analysis of the VHL gene obtained in each patient confirmed the genetic diagnosis. All patients were operated on by the same surgeon (GP). Preoperative angiography, endovascular embolization, intraoperative monitoring and ultrasonography were never utilized. Three patients showed hydrocephalus on admission, with one requiring an external ventricular drainage. Lesions were approached through a suboccipital craniotomy tailored on an individual basis in case of multiple lesions, and enlarging the caudal exposure by $\mathrm{C} 1$ laminectomy and $\mathrm{C} 2$ partial drilling if necessary. A sitting position was preferred, while patients with already implanted ventriculo-peritoneal shunts were positioned prone.

\section{Results}

The mean interval time lasting from the first symptoms' onset and operation was 8.5 months (range $0-24$ ). One patient was asymptomatic, and the decision to operate was based on a progressive increase of the solid hemangioblastoma on serial MR imaging. The most frequent preoperative symptoms included headache and cervical pain, followed by long tract signs and nuclear involvement (Fig. 1). Preoperatively three patients showed a KPS lower than 80 , ten patients between 80 and 90 , and one patient scored 100 (asymptomatic). Hemangioblatomas were located at the obex area in ten cases and along the dorso-lateral aspect of the bulb in four cases. They were mainly dorsal exophytic (Fig. 2), while a focal intramedullary situation was less common (four cases). Maximum diameter of the nodule ranged between 3 and $21 \mathrm{~mm}$. In two cases only the solid component of the hemangioblastoma was found. In one patient two hemangioblastomas within the bulbar syrinx were removed. In five patients intraoperative episodes of bradycardia occurred during tumor dissection; they were managed pharmacologically and by reducing surgical traction.

During the postoperative course only three patients required prolonged monitoring in the intensive care unit (ICU): one for a tracheostomy (16 days), another for a close monitoring of external ventricular drainage (4 days) and a third for hyponatremia ( 3 days). The other 11 patients were discharged to a regular ward the day after surgery. Mean length of ICU occupancy was 2.4 days. A transient postoperative morbidity (new symptoms or worsening of pre-existing symtoms) was observed in nine patients (64\%): paresis and hypoesthesia of the hand and lower cranial nerve functional impairment were the more common complaints. At follow-up 11 patients (78.5\%) showed no residual neurological deficit related with the brain stem hemangioblastoma, while three patients showed a stable neurological deficit (one diplopia, one paresis and hypoesthesia of the hand, and one mild swallowing impairment). Considering long-term functional outcome, ten patients

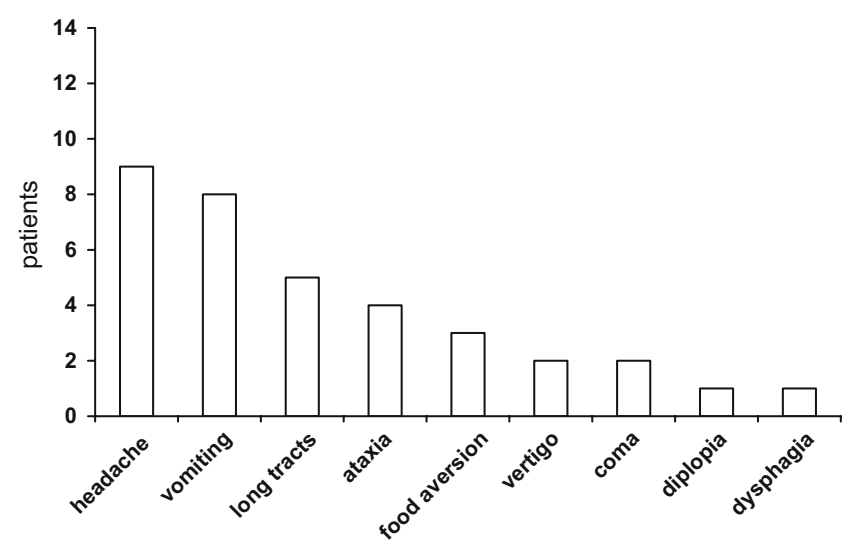

Fig. 1 Preoperative symptoms and their frequency 
Fig. 2 Preoperative contrastenhanced MR (a, b) showing a typical hemangioblastoma at the obex with an exophytic location and an associated bulbar syrinx; 1 year after surgery MR $(\mathbf{c}, \mathbf{d})$ showing complete removal of the lesion and disappearance of the cystic component (patient no. 9)
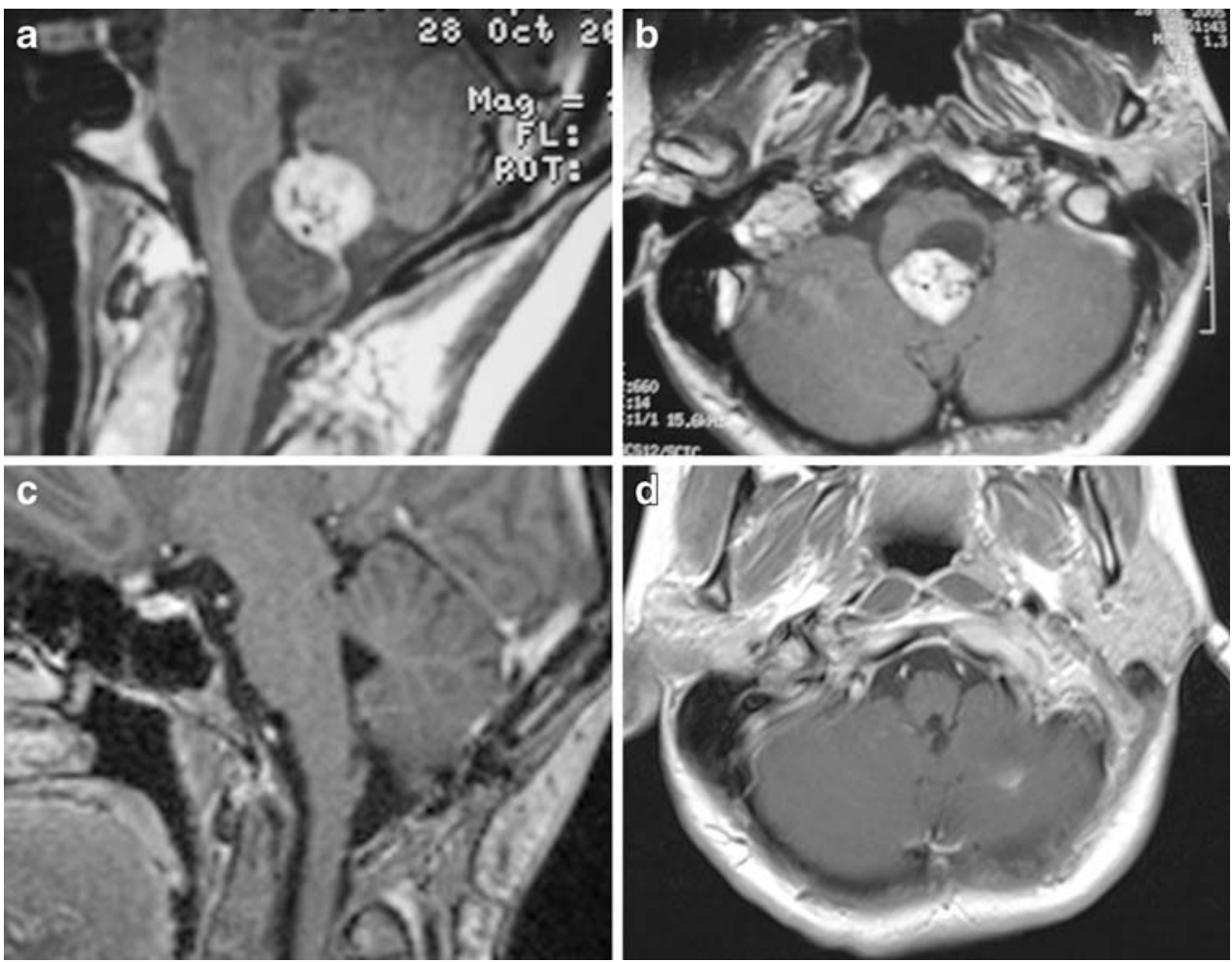

scored a KPS better than before the operation, and four patients remained stable. When comparing long-term KPS with KPS at discharge, one patient showed a worsened KPS at follow-up because of clinical progression of multiple cervical hemangioblastomas (patient no. 5, Table 1). MR follow-up confirmed the total excision of the operated hemangioblastomas, the disappearance of the associated cyst and resolution of hydrocephalus whenever present (Fig. 3). Table 1 summarizes the most relevant clinical features of our patients.

\section{Discussion}

\section{Clinical presentation}

In our experience $18 \%$ of patients with VHL show lower brain stem localization of hemangioblastomas. Other series report comparable figures $[4,6,9,17]$. Thus, when dealing with VHL disease, symptoms and signs correlated with bulbar function should be investigated carefully, since they may be difficult to assess during standard neurological examinations. In particular, food aversion with body weight loss and stomach ache is a misleading clinical onset related with vagal nuclear involvement by obex compression [14, 19]. Even though our series is homogeneous for what concerns the anatomical site of growth, preoperatively we observed an assortment of different clinical features that can be explained by the functionally crowded area of the dorsal medulla oblongata.

Also the interval between clinical onset and surgery is variable, ranging from weeks to years. Our observations concerning the clinical progression of neurological symptoms are considerably influenced by the close surveillance to which these patients are submitted once VHL diagnosis is established, and, therefore, their therapeutic management is generally shortened in terms of surgical timing. However, it is noteworthy that $11 / 14$ patients $(78 \%)$ showed a KPS between 80 and 100 before surgery, meaning that they were able to carry on normal activities in the presence of at least some minor symptoms. These remarks suggest that brain stem hemangioblastomas behave as slow-growing tumors causing a gradual clinical progression, which usually allows an elective surgery setting. Conversely, in three cases we observed a rapid clinical onset, correlated with obstructive hydrocephalus development, requiring an early timing of surgery.

\section{Surgical outcome}

Operability assessment for brain stem hemangioblastomas in VHL patients develops out of a multiorgan pathology and in a context of multiple CNS lesions. The natural history of hemangioblastomas in VHL is characterized by the alternation of variable periods of quiescence and periods of growth $[1,18,23]$, making the prognosis of the 
Table 1 Clinical findings of patients operated on for brain stem hemangioblastoma

\begin{tabular}{|c|c|c|c|c|c|c|c|c|c|}
\hline $\begin{array}{l}\text { Patient } \\
\text { no. }\end{array}$ & Age & $\begin{array}{l}\text { Clinical onset } \\
\text { (months) }\end{array}$ & Location & $\begin{array}{l}\text { Preop } \\
\text { KPS }\end{array}$ & $\begin{array}{l}\text { Discharge } \\
\text { KPS }\end{array}$ & $\begin{array}{l}\text { Last } \\
\text { follow-up } \\
\text { KPS }\end{array}$ & $\begin{array}{l}\text { Temporary } \\
\text { complications }\end{array}$ & $\begin{array}{l}\text { Persistent } \\
\text { deficits }\end{array}$ & $\begin{array}{l}\text { Follow-up } \\
\text { (months) }\end{array}$ \\
\hline 1 & 23 & 24 & Median & 10 & 50 & 60 & $\begin{array}{l}\text { Lower cranial nerves } \\
\text { palsy, diplopia }\end{array}$ & Diplopia & 99 \\
\hline 2 & 34 & 5 & Lateral & 80 & 90 & 100 & $\begin{array}{l}\text { Hand paresis and } \\
\text { paresthesia }\end{array}$ & & 96 \\
\hline 3 & 47 & 3 & Median & 90 & 100 & 100 & & & 52 \\
\hline 4 & 30 & 1 & Lateral & 70 & 100 & 100 & $\begin{array}{l}\text { Lower cranial nerves } \\
\text { palsy }\end{array}$ & & 42 \\
\hline 5 & 28 & 18 & Median & 80 & 100 & 80 & & & 27 \\
\hline 6 & 25 & 0 & Median & 100 & 100 & 100 & & & 25 \\
\hline 7 & 30 & 6 & Lateral & 80 & 80 & 80 & & & 19 \\
\hline 8 & 31 & 14 & Median & 80 & 80 & 90 & & & 17 \\
\hline 9 & 29 & 1 & Median & 90 & 80 & 90 & $\begin{array}{l}\text { Diplopia, hand paresis, } \\
\text { lower cranial nerves }\end{array}$ & $\begin{array}{r}\text { Swallowing } \\
\text { discomfort }\end{array}$ & 15 \\
\hline 10 & 31 & 12 & Median & 80 & 100 & 100 & $\begin{array}{l}\text { Hand paresis and } \\
\text { dysesthesia }\end{array}$ & & 13 \\
\hline 11 & 56 & 1 & Median & 30 & 100 & 100 & Hiccup, dysphonia & & 13 \\
\hline 12 & 22 & 3 & Median & 80 & 90 & 90 & $\begin{array}{l}\text { Hand paresis and } \\
\text { dysesthesia }\end{array}$ & Hand paresis & 12 \\
\hline 13 & 50 & 3 & Median & 80 & 80 & 90 & Cerebellar ataxia & & 11 \\
\hline 14 & 35 & 20 & Lateral & 80 & 90 & 90 & Vertigo & & 4 \\
\hline
\end{tabular}

KPS $=$ Karnofsky Performance Status

clinical picture difficult to assess. Especially the concomitancy of other symptomatic CNS hemangioblastomas makes it difficult to evaluate the clinical priority among different localizations. Anyway, although VHL disease has a severe impact on long-term prognosis in relation to median length of life [10], what emerges from the literature $[13,26]$ and from our observations is that VHL patients with symptomatic or growing bulbar hemangioblastomas are young adult patients that benefit from surgical resection of these lesions in terms of symptom recovery or stabilization. There are previous reports regarding surgery of brain stem hemangioblastomas showing the efficacy of microsurgical treatment, but without distinguishing between VHL-associated and sporadic hemangioblastomas $[2,20,21,24]$; actually, it has been observed that there is no difference in terms of functional outcome between VHL and non-VHL patients with surgically treated medulla oblongata hemangioblastomas [13]. Weil et al. [26] reported a series of $12 \mathrm{VHL}$ patients operated on for brain stem hemangioblastomas with a final surgical outcome (11/ 12 remained stable or improved) similar to our observations, although we, as well as other authors $[2,16,21,24$, 27], noted a higher rate of postoperative transient morbidity; at follow-up all our patients were stable (4 patients) or improved (10 patients) when compared with preoperative overall conditions. Thus, microsurgery, with the support of adequate postoperative care to manage transitory failures of neurological functions, offers a safe and effective treatment in these patients. Persistent neurological sequelae are more probably linked to the degree of tumor adhesion to the floor of the inferior triangle of fourth ventricle, and the consequent difficulty in leaving the neural tissue intact, however delicate the dissection. Therefore, it appears that a key role in the management of brain stem hemangioblastomas is played by serial combined clinical and MRimaging surveillance in these patients, allowing an early diagnosis and the choice of the most appropriate timing for surgery, in order to avoid severe clinical deterioration before treatment. Thus, we recommend surgical therapy when brain stem symptoms correlate with MR findings or when the solid lesion or the associated cyst show a significant volume increase even in asymptomatic patients.

\section{Surgical technique}

Concerning the surgical management, our patients were treated without intra-operative monitoring: even if this technological innovation may help direct surgery in highly functional areas, in the specific case of hemangioblastomas its use is not mandatory since (1) there is no problem of visual demarcation between tumor and normal tissue; (2) a superficial part of the lesion is usually apparent once the dura is opened and/or entering the associated cyst may help to reach a deeper location; (3) any attempt of partial 

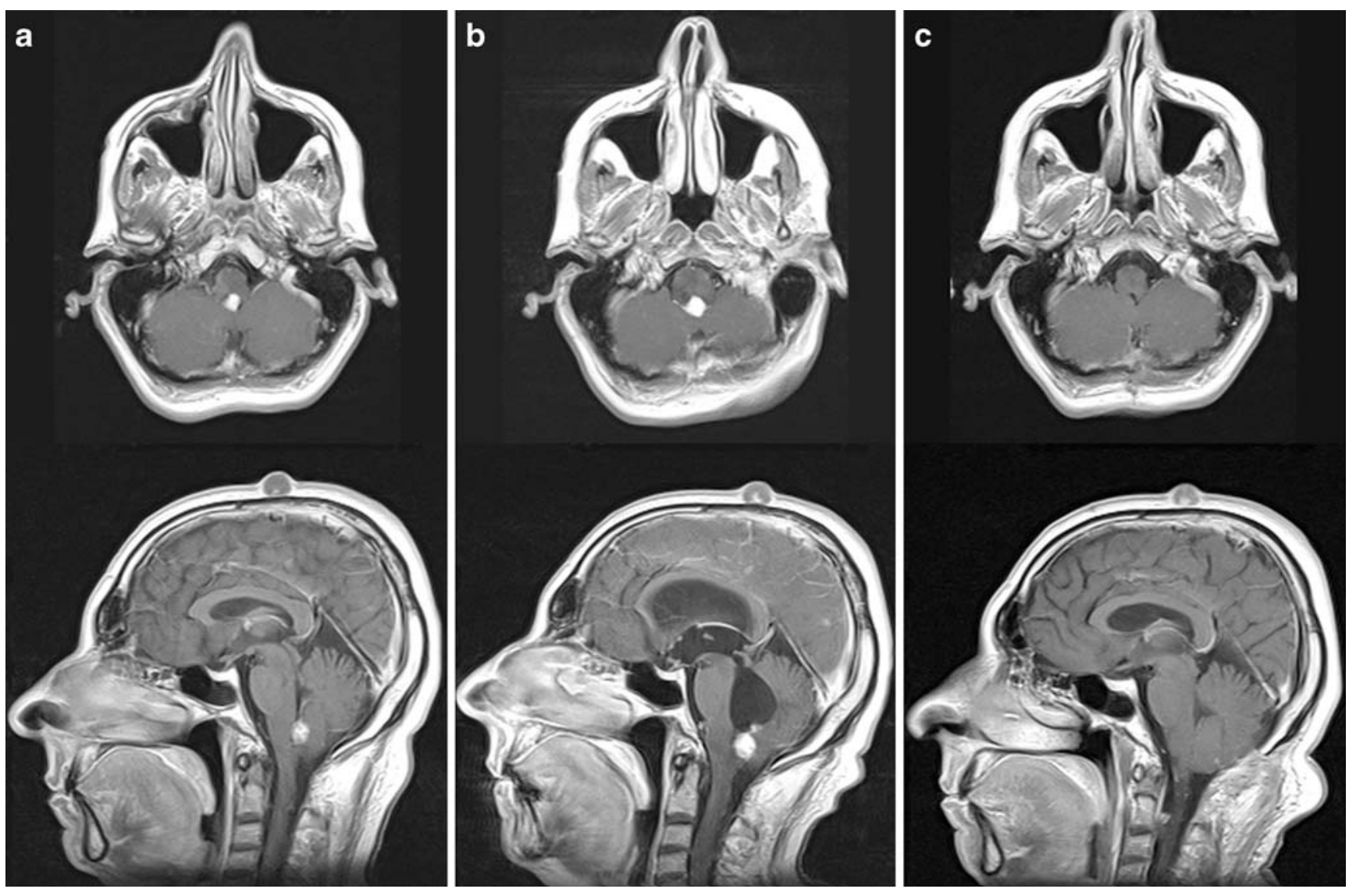

Fig. 3 Clinical and radiological progression of a medullary hemangioblastoma (patient no. 11): asymptomatic small hemangioblastoma at the obex (a); acute hydrocephalus associated with an increase in

surgical removal must be avoided owing to the conspicuous vascularization of these tumors. Actually, it is crucial to find and follow the arachnoidal plane that, under high magnification, always marks the boundary between the lesion and neural tissue. Intraoperative bradycardia may occur, and it always is resolved either pharmacologically or by reducing undue distraction of the surrounding nerve pathways during dissection of the lesion. Intraoperative bleeding is not a major concern since the lesion is handled gently and not entered during its progressive devascularization conducted by properly low-set bipolar coagulation; whenever hemorrhage occurs during tumor dissection, cottonoid compressive hemostasis is usually an adequate means to keep the operative field clear until devascularization is completed. Although cyst excision was not usually attempted, in two cases it was necessary to open its wall wide with the purpose of releasing a trapped fourth ventricle. After surgery these patients need careful neurological monitoring, especially for the risk of transient difficulties in swallowing and raising sputum, which may need specific prophylactic and rehabilitative measures in order to avoid aspiration pneumonia. volume of the nodule (b); hydrocephalus resolution after complete removal of the tumor

\section{Treatment alternatives}

Some authors consider radiosurgery for intracranial hemangioblastomas [8, 12, 22, 25], but experience with the brain stem location is limited: the presence of an often symptomatic cystic component and the functional eloquence of the surrounding tissue seems to restrict the long-term efficacy and the safety of radiosurgery for lower brain stem hemangioblastomas $[3,7,11]$. Since microsurgery provides safe, immediate and complete cure of the lesion, we believe that it is the first-choice therapeutic option and that radiosurgery for brain stem hemangioblastomas may play a role for patients who are not surgical candidates [5].

\section{Conclusions}

Lower brain stem hemangioblastomas in the context of VHL show an often gradual onset of signs and symptoms except for patients who develop an obstructive hydrocephalus. Serial clinical and MR-imaging examinations are essential to provide early diagnosis and appropriate thera- 
peutic decisions. Although transient surgical complications are possible, surgery offers complete removal with acceptably low risk, achieving favorable long-term results.

\section{References}

1. Ammerman JM, Lonser RR, Dambrosia J, Butman JA, Oldfield EH (2006) Long-term natural history of hemangioblastomas in patients with von Hippel-Lindau disease: implications for treatment. J Neurosurg 105:248-255

2. Bricolo A, Turazzi S (1995) Surgery for gliomas and other mass lesions of the brainstem. Adv Tech Stand Neurosurg 22:261-341

3. Chang SD, Meisel JA, Hancock SL, Martin DP, McManus M, Adler JR Jr (1998) Treatment of hemangioblastomas in von Hippel-Lindau disease with linear accelerator-based radiosurgery. Neurosurgery 43:28-35

4. Filling-Katz MR, Choyke PL, Oldfield E et al (1991) Central nervous system involvement in von Hippel-Lindau disease. Neurology 41:41-46

5. Jawahar A, Kondziolka D, Garces YI, Flickinger JC, Pollock BE, Lunsford LD (2000) Stereotactic radiosurgery for hemangioblastomas of the brain. Acta Neurochir 142:641-644

6. Maher ER, Webster AR, Moore AT (1995) Clinical features and molecular genetics of Von Hippel-Lindau disease. Ophtalmic Genet 16:79-84

7. Matsunaga S, Shuto T, Inomori S, Fujino H, Yamamoto I (2007) Gamma knife radiosurgery for intracranial haemangioblastomas. Acta Neurochir 149:1007-1013

8. Moss JM, Choi CY, Adler JR Jr, Soltys SG, Gibbs IC, Chang SD (2009) Stereotactic radiosurgical treatment of cranial and spinal hemangioblastomas. Neurosurgery 65:79-85

9. Neumann HP, Eggert HR, Weigel K, Friedburg H, Wiestler OD, Schollmeyer P (1989) Hemangioblastomas of the central nervous system. A 10-year study with special reference to von HippelLindau syndrome. J Neurosurg 70:24-30

10. Niemela M, Lemeta S, Summanen P et al (1999) Long term prognosis of haemangioblastoma of the CNS: impact of von Hippel-Lindau disease. Acta Neurochir 141:1147-1156

11. Niemela M, Lim YJ, Soderman M et al (1996) Gamma knife radiosurgery in 11 hemangioblastomas. J Neurosurg 85:591-596

12. Park YS, Chang JH, Chang JW, Chung SS, Park YG (2005) Gamma knife surgery for multiple hemangioblastomas. J Neurosurg 102:97-101

13. Parker F, Aghakhani N, Ducati LG et al (2009) Results of microsurgical treatment of medulla oblongata and spinal cord hemangioblastomas: a comparison of two distinct clinical patient groups. J Neurooncol 93:133-137

14. Pavesi G, Berlucchi S, Feletti A, Opocher G, Scienza R (2006) Hemangioblastoma of the obex mimicking anorexia nervosa. Neurology 67:178-179

15. Pavesi G, Feletti A, Berlucchi S, Opocher G, Martella M, Murgia A, Scienza R (2008) Neurosurgical treatment of von Hippel-Lindauassociated hemangioblastomas: benefits, risks and outcome. J Neurosurg Sci 52:29-36

16. Rachinger J, Buslei R, Prell J, Strauss C (2009) Solid haemangioblastomas of the CNS: a review of 17 consecutive cases. Neurosurg Rev 32:37-47

17. Richard S, David P, Marsot-Dupuch K, Giraud S, Beroud C, Resche F (2000) Central nervous system hemangioblastomas, endolymphatic sac tumors, and von Hippel-Lindau disease. Neurosurg Rev 23:1-24

18. Slater A, Moore NR, Huson SM (2003) The natural history of cerebellar hemangioblastomas in von Hippel-Lindau disease. Am J Neuroradiol 24:1570-1574

19. Song DK, Lonser RR (2008) Pathological satiety caused by brainstem hemangioblastoma. J Neurosurg Pediatrics 2:397-401

20. Spetzger U, Bertalanffy H, Huffmann B, Mayfrank L, Reul J, Gilsbach JM (1996) Hemangioblastomas of the spinal cord and the brainstem: diagnostic and therapeutic features. Neurosurg Rev 19:147-151

21. Symon L, Murota T, Pell M, Bordi L (1993) Surgical management of haemangioblastoma of the posterior fossa. Acta Neurochir 120:103-110

22. Tago M, Terahara A, Shin M, Maruyama K, Kurita H, Nakagawa K, Ohmoto K (2005) Gamma knife surgery for hemangioblastomas. J Neurosurg 102:171-174

23. Wanebo JE, Lonser RR, Glenn GM, Oldfield EH (2003) The natural history of hemangioblastomas of the central nervous system in patients with von Hippel-Lindau disease. J Neurosurg 98:82-94

24. Wang C, Zhang J, Liu A, Sun B (2001) Surgical management of medullary hemangioblastoma. Report of 47 cases. Surg Neurol 56:218-226

25. Wang EM, Pan L, Wang BJ, Zhang N, Zhou LF, Dong YF, Dai JZ, Cai PW, Chen H (2005) The long-term results of gamma knife radiosurgery for hemangioblastomas of the brain. J Neurosurg 102:225-229

26. Weil RJ, Lonser RR, DeVroom HL, Wanebo JE, Oldfield EH (2003) Surgical management of brainstem hemangioblastomas in patients with von Hippel-Lindau disease. J Neurosurg 98:95-105

27. Zhou LF, Du G, Mao Y, Zhang R (2005) Diagnosis and surgical treatment of brainstem hemangioblastomas. Surg Neurol 63:307315 